\title{
BIOLOGÍA Y MEDICINA REDUCCIONISTAS: UNA REFLEXIÓN SOBRE SUS RAÍCES EPISTEMOLÓGICAS Y SUS LIMITACIONES
}

\section{REDUCTIONIST BIOLOGY AND MEDICINE: A REFLECTION CONCERNING THEIR LIMITS AND EPISTEMOLOGCAL ROOTS}

\author{
Julio Muñoz Rubio \\ Investigador independiente \\ Ciudad de México, México \\ juliomunozr2000@yahoo.es
}

Recibido: 3 de maro de 2021 / Aprobado: 12 de abril de 2021 / Publicado: 30 de junio de 2021

\begin{abstract}
Resumen
La masiva inoculación de vacunas preventivas del COVID es el más reciente acontecimiento en el que las empresas farmacéuticas y la ciencia médica dependiente de ellas imponen su visión de lo que deben ser los tratamientos preventivos. Estos han estado históricamente basados en una concepción reduccionista y mecanicista del cuerpo humano y de los procesos de la vida, que está siendo crecientemente cuestionada en favor de concepciones más integrativas, relacionales y de la totalidad en el mundo vivo. Sin menospreciar los logros que aquella concepción médica ha tenido, sí se considera indispensable aprovechar la situación sanitaria mundial presente para abrir una reflexión crítica sobre los fundamentos metodológicos de la medicina hegemónica; exhibir tanto sus aciertos como sus limitaciones y dirigir estos esfuerzos a la construcción de una medicina ontológico-epistémicamente plural y despojada de su dependencia de los grandes consorcios farmacéuticos.
\end{abstract}

Palabras clave: Ciencia médica, reduccionismo, industria farmacéutica, causalidad, complejidad.

\begin{abstract}
The current massive inoculation of COVID preventive vaccines is the most recent event in which multinational pharmaceutic companies and medical science dependent on them, impose their vision of what the preventive medical treatments must be. Historically speaking, these have been based in a reductionist and mechanicist conception of human body and of
\end{abstract}


the whole of living processes. This conception has been increasingly criticized in favor of a more integral, relational and whole-based visions of living beings. Without belittling the achievements of reductionist medical approach, I consider indispensable to take advantage of the present world-wide sanitary situation in order to open a critical reflection on the methodological foundations of hegemonic medicine. These efforts should be addressed to the construction of an ontological-epistemic plural medical science, stripped of its dependence in large pharmaceutical consortia.

Key words: Medical science, reductionism, pharmaceutical industry, causal relations, complexity.

\section{Introducción}

$\mathrm{E}$ 1 reciente descubrimiento y comercialización de vacunas para combatir la pandemia del virus SARS-CoV-2 ha sido celebrado tanto por las empresas privadas que las han fabricado como por los gobiernos de los países a los que han llegado para su aplicación. Simultáneamente, se han levantado ciertas objeciones a la aplicación de estos medicamentos con base en argumentos que van desde la duda de su eficacia y de los efectos secundarios que pueda tener, a un alegato defensor de otro tipo de terapias.

Dentro de este debate, llama la atención que no se esté poniendo atención ni a las raíces históricas ni a los fundamentos ontológico-epistemológicos de la elaboración de las vacunas. Se parte de su existencia, pero no se les comprende integralmente.

Por ello, y en vez de adentrarme en el análisis de las características, ventajas y desventajas de cada una de tales vacunas, desarrollo un análisis de las concepciones ontológico-epistemológicas que subyacen a la medicina hegemónica y de sus contradicciones, intentando motivar el inicio de una reflexión ulterior (materia de otros textos) sobre la pertinencia de esas masivas vacunaciones y sobre la posibilidad de una pluralidad en la ciencia médica en general.

La metodología usada se basa en mostrar las contradicciones dialécticas existentes entre las dos grandes concepciones de los seres vivos y de los procesos de salud-enfermedad: la reduccionista y la totalizadora o relacional y a partir de allí desarrollar una argumentación que nos lleve a considerar la superación del reduccionismo dentro de un nuevo sistema onto-epistémico médico. 
El texto se divide en 5 partes: Un repaso por la concepción reduccionista cartesiana desde el siglo XVII; un examen sobre su influencia en la biología, una disertación sobre cómo esta influencia se expresa en la medicina, una mención a la crítica contemporánea al reduccionismo en los seres vivos y el cuerpo humano y, finalmente, una defensa de la pluralidad metodológica en la medicina mediante la incorporación de concepciones no reduccionistas y más bien relacionales, totalizadoras y dialécticas.

\section{El reduccionismo en ciencia: Raíces y confrontaciones}

Una de las características de la filosofía moderna, con base en la cual se ha construido la ciencia que conocemos, es la de su noción de causalidad, que sostiene que la causa y el efecto de cualquier fenómeno siguen siempre una relación 1 a 1. Así, una causa produce un efecto y solo uno, una causa determinada siempre producirá el mismo efecto y siempre la causa precederá al efecto. Causa y efecto se encuentran separados uno con respecto al otro y preexisten a cualquier contexto. Para esta filosofia, el todo de un sistema dado es igual a la suma de sus partes y es en la partícula considerada como más básica, fija e incambiable donde se encuentra la propiedad pretendidamente esencial, la cual será transmitida al todo. Se ha mencionado que esa es una concepción que forma parte de la visión burguesa del mundo (Levins y Lewontin, 1985, pp 267-288).

Se ha señalado a René Descartes como el principal proponente de los fundamentos de esta concepción reduccionista y determinista del mundo (Descartes, 1989, 1995, 1996 a, 1996 b). Descartes aportó una sólida teoría epistemológica, extensible, con sus diferencias, a la filosofía de los siglos XVI al XIX tales como a Hobbes (2001), Hume (1992, 2000), Leibniz (2018), Locke (2005), Mill (1904) o de la Mettrie (1962).

Estos trabajos determinaron grandes verdades o vías para llegar a ellas; se elaboraron leyes que permanecen hasta la fecha mostrando toda su validez. Todas ellas han ampliado nuestro conocimiento del mundo como nunca antes, han alcanzado progresos indiscutibles en ciencia y tecnología y han ambicionado, no sin generar serios conflictos, la construcción de una cultura basada en la razón. En este sentido se puede afirmar que la ciencia reduccionista ha jugado un papel revolucionario, lo cual, no obstante, no es eterno ni está exento de contradicciones. 
Ahora bien, la ciencia reduccionista ha mostrado sus límites cuando, como resultado de su desarrollo, se comenzaron a plantear problemas de naturaleza distinta a los de los siglos XVI al XVIII y se pasó, de estudiar sistemas de la física clásica a sistemas complejos como los biológicos, económico-sociales, psicológicos y mentales, así como los de la física atómica y subatómica. La ciencia reduccionista había sido tan fructífera que se supuso que sus bases metodológicas podrían utilizarse para comprender cualquier fenómeno del universo. Al defender esa ortodoxia, no se tomó en cuenta el cambio cualitativo que estos estudios más recientes tuvieron y tienen. Me refiero a las teorías de la economía política, con Adam Smith (1954), al psicoanálisis (Freud, 2017), a la sociología de Weber (1964) o Durkheim (2001), entre otras; al materialismo histórico de K. Marx y F. Engels (1977) y a la biología evolutiva, de Lamarck (1809) a Darwin (1964) y al presente.

Se trata de sistemas en los que coexisten multitud de variables y donde es complicado tanto hacer extrapolaciones y predicciones exactas, como conocer el carácter preciso de las relaciones causa-efecto. Sistemas donde se admite que los todos son cualitativamente distintos a la suma de las partes, no existe una jerarquía fija para las variables que en estos procesos intervienen y frecuentemente, al replicar un experimento, se encuentra que pequeñas variaciones en las condiciones iniciales del sistema estudiado dan resultados muy diferentes al final del proceso (Caparrós y Cruz Roche, 2012).

A partir de este conocimiento complejo se generó también la reflexión sobre la necesidad de impulsar una investigación inter y transdisciplinaria, como alternativa al curso súper especializado y fragmentador de la ciencia cartesiana (Caparrós y Cruz Roche, 2012; García, 2007; González Casanova, 2004; Morín, 2007).

El poder del reduccionismo ha llevado a ignorar el papel que el conocimiento complejo ha tenido conforme transcurre el tiempo y ha seguido, dígase una vez más, tratando los procesos, naturales y sociales, como si fueran los de la física de hace 4 siglos, particularmente en biología y medicina. Además, se han construido aplicaciones de la complejidad adaptándola a los dictados reduccionistas, fetichizando ciertas categorías de análisis y entes y considerándolos como los "esenciales" para construir modelos de una deficiente complejidad, al servicio de los poderes fácticos capitalistas (González Casanova, 2004). 
Esto último es claro en los estudios de nuevas tecnologías impulsadas por las grandes empresas trasnacionales, donde se coincide con las metodologías reduccionistas, por ejemplo, en la biotecnología, la nanotecnología, la genómica, la geoingeniería, el neo-malthusianismo, y parte considerable de la medicina alopática.

Así, la dependencia de la ciencia con respeto a los poderes fácticos se incrementa, lo cual redunda en un debilitamiento de su autonomía frente a las esferas económicas o políticas, y con ello se convierte en empresa donde la pluralidad, el debate y la disidencia racionales se ven limitadas o canceladas (Bordieu, 2003, p. 7).

Los fundamentos y metodología del modelo reduccionista han penetrado en la conciencia colectiva de amplios sectores de la sociedad civil, más allá de la comunidad científica y se han aceptado los conceptos de prueba, evidencia, observación, corroboración, experimento, objetividad y verdad. Sin embargo, este proceso ha quedado limitado a las reglas del reduccionismo (y más tarde con las aportaciones del positivismo) y a sus relaciones de causalidad. Erróneamente se ha pensado que ese modelo es el único existente, desmereciendo o ignorando las aportaciones de las ciencias de la complejidad. Desacertadamente, también, se ha difundido una imagen de la ciencia como actividad que sigue un curso inexorable hacia la verdad y la acumulación de conocimiento; la ciencia imaginada como empresa monolítica y homogénea.

Con todo esto, podemos afirmar que la ciencia reduccionista, de haber jugado un carácter revolucionario, devino en empresa conservadora y atadura del progreso científico; de ser símbolo de una burguesía pujante, creativa e innovadora, pasó a ser el de una clase decadente y destructiva; de una ciencia liberadora se trocó en empresa autoritaria y opresiva; de actividad productora de grandes conocimientos benéficos para la humanidad, se transformó en habilidad impulsora de técnicas al servicio de minorías capitalistas.

\section{La Influencia del reduccionismo en la biología}

Es en biología donde ha ocurrido una clara confrontación entre la visión reduccionista y las teorías de la complejidad; aquí se ha hecho presente el conflicto entre las concepciones esencialistas, parciales y fragmentarias contra las visiones relacionales y de la totalidad. En genética y biología molecular se ha dado mucho de esta confrontación. Aquí el reduccionismo 
ha buscado explicar los mecanismos transmisores de información de una generación a otra, pensando que deben residir en una partícula poseedora de tal información y con la capacidad de llevar a cabo su transmisión independientemente del medio en el que se encuentre.

Con esta tesis en mente se originó, a fines del siglo XVIII, la llamada teoría preformista, que sostenía que en los óvulos humanos existía un ser en miniatura llamado "homúnculo", que sería activado con la energía del espermatozoide, aumentando así su tamaño hasta dar lugar a un individuo maduro (Bowler, 2003 pp. 46-47, 65-66). Aunque esa teoría tal cual fue descartada, su idea central se ha mantenido hasta el presente. Durante el siglo XIX, adoptando modalidades distintas, Mendel (1965), Darwin (1969) y Weismann (1882) impulsaron esa idea básica, afirmaron que debía existir una partícula última, totipotencial y separada del ambiente que contuviera el mensaje hereditario. Es el concepto de "herencia dura". En las primeras décadas del siglo XX, la síntesis moderna, consistente en una fusión entre la genética mendeliana y la selección natural darwiniana, postuló a la variación azarosa (propia de la herencia dura), a la adaptación y a la selección natural como los pasos del mecanismo evolutivo universal. Todo esto conoció impulsos posteriores con el descubrimiento de la estructura de la célula eucarionte, de la función del núcleo como el organelo donde reside el material hereditario, de los cromosomas, del concepto de gen y su composición química, para alcanzar un punto máximo en 1953 con la determinación de la estructura tridimensional de los ácidos nucleicos (Watson y Crick, 1953a, 1953b), esfuerzo que sería coronado por Crick (1970), con la postulación del dogma central de la biología molecular (DCBM).

El DCBM establece que la información genética fluye siempre desde el ADN al ARN y de ahí a las proteínas, o a veces directamente a ellas sin mediación del ARN. El ADN también lleva a cabo un permanente proceso de autorreplicación y las enzimas reverso-transcriptasas permiten un ocasional flujo de información desde el ARN al ADN. ELARN es capaz de autorreplicarse ocasionalmente también. Crick postula este mecanismo como principio universal, por ello lo llama “dogma” (Figura 1). 


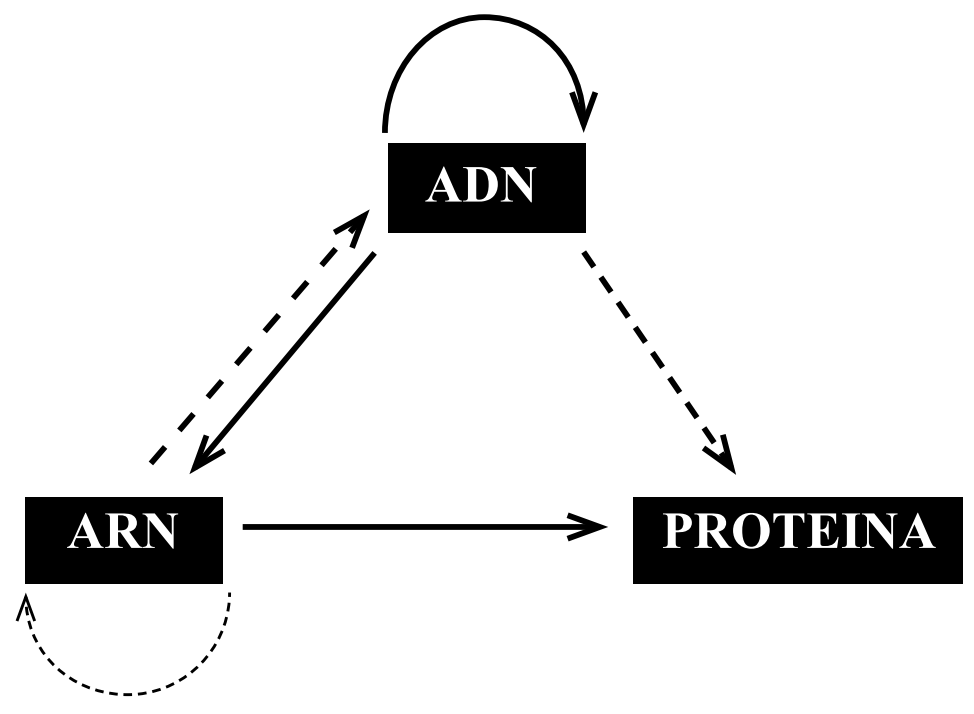

Figura 1: Dogma central de la biología molecular (Tomado de Crick, 1970).

Esta corriente en biología lleva a sus últimas consecuencias la tesis de que los seres vivos están compuestos de partículas últimas que contienen la esencia de sus propiedades, capaces de generarlas y transmitirlas a la descendencia. Estas partículas son los ácidos nucleicos: ADN y ARN.

Parecía completada una titánica tarea. Se asumió que el "secreto" de la herencia había sido descubierto hasta en sus más mínimos detalles. Se comprendía que las correspondencias gen-proteína y genotipo-fenotipo, seguían el principio de relaciones causa-efecto 1 a 1 y como partes esenciales, cuya suma constituye a los todos de cada individuo. Además, se afirmó que la "esencia de la vida" había sido develada, siguiendo el principio cartesiano de que para conocer verdaderamente un objeto o sistema de estudio es necesario descomponerlo en sus partes hasta llegar a la más simple de ellas (Descartes, 1995, parte segunda: 23). Así, la esencia debía entenderse como propiedad inalterable, como una cosa depositada en la partícula más elemental del objeto a estudiar. Es decir, para los seres vivos se hizo una reificación de la esencia, entendiéndola como algo existente al margen de toda relación (Descartes, 1995, parte primera: 51), provista de una misteriosa 
propiedad que la hace autorreferencial y autosuficiente. Este es el modelo genocéntrico del mundo vivo.

Así, los ácidos nucleicos contendrían todas las propiedades de los seres vivos. Se trata de una reformulación del preformismo, actualizada a los conocimientos del siglo XX y XXI. El homúnculo es sustituido por el gen y por el ácido nucleico. El individuo se explica por su parte considerada la más esencial: la célula, y esta, a su vez, por su núcleo; este por sus cromosomas y estos por los ácidos nucleicos que contiene. A la descomposición del todo en sus partes constitutivas, y habiendo llegado a la partícula última, se sigue un proceso inverso que va de lo más simple a lo más complejo, en el que lo segundo se deriva unidireccionalmente del primero. Lewontin (1991) señala que la raíz de esta concepción consiste en una extrapolación de uno de los principales elementos de la revolución burguesa: el individuo y su racionalidad como la parte esencial de la sociedad, donde resulta esta de la suma de sus esencias.

Esta idea de los ácidos nucleicos como la "partícula viviente" esencial nos remite a las tesis del fetichismo de la mercancía (Marx, 1988, pp. 87-102), del fetichismo del dinero en el campo del crédito, donde el dinero parece originarse a partir de sí mismo (Marx, 1985, pp. 499-501) y en la de la circulación de mercancías, donde el dinero nunca se retira de ella (Marx, 1987a, pp.73-111).

\section{El reduccionismo en medicina}

Esta concepción reduccionista atraviesa la medicina hegemónica. Los seres humanos son entendidos como máquinas, sistemas en los que su funcionamiento se explica por la disposición espacial de sus partes, independientes entre sí. Al detectarse una falla que produzca una enfermedad, se acude a averiguar en qué órgano ocurre y se le intenta reparar independizándolo con respeto al todo, fragmentando los cuerpos en múltiples trozos.

El cuerpo humano y el combate a la enfermedad se entienden como un sistema newtoniano de fuerzas. Con base en él se elaboran sistemas de medicación consistentes en fuerzas de sentido y magnitud contrarios a los de la fuerza causante del padecimiento: si hay dolor se administra un analgésico, antiinflamatorios para las hinchazones, antihistamínicos en los casos 
de alergia, antibióticos cuando hay infecciones, relajantes al presentarse tensión nerviosa, somníferos donde haya insomnio, todo recetado en dosis proporcionales a la intensidad del síntoma. La cirugía acude para extraer las partes irreversible o seriamente dañadas, y para para prevenir las infecciones y las enfermedades están las vacunas. Un claro esquema reduccionista.

Como en la física de Newton, en la medicina hegemónica todo movimiento tiende a mantenerse en estados de regularidad y de equilibrio; la enfermedad es un abandono o salida temporal de un individuo con respecto a su estado de "normalidad", es una condición excepcional que tarde o temprano encontrará un retorno "natural" a la "armonía", entendida como "salud."

No debe olvidarse el genocentrismo. En teoría médica contemporánea se puede admitir que la explicación última de las enfermedades tiene una naturaleza genética, un "desarreglo" en el contenido de los ácidos nucleicos, o en la trasmisión de información (Stearns y Coella, 2008, Taylor, 2015). Fallas metabólicas, enzimáticas o inmunológicas son remitidas a las secuencias génicas del individuo, es la explicación subyacente.

A partir de todo esto se construye un aparato teórico, técnico y administrativo que empapa toda la medicina hegemónica. Se trata de la formación de los médicos, tendiente a las superespecializaciones; planes de estudio y líneas de investigación, la estructura de hospitales y clínicas, la tecnología usada y la preeminencia de la industria químico-farmacéutica. Todo corresponde a la noción reduccionista y genocéntrica descrita en párrafos anteriores, parte central de la hegemonía capitalista.

Al hacer estos señalamientos no se busca negar los avances de la medicina reduccionista en el control de enfermedades infecciosas, elevación de esperanzas y de promedio de años de vida, abatimiento de tasas de mortalidad y contagio. Ninguna ciencia médica futura podrá negar ni abandonar todos estos conocimientos y sus alcances. Lo que se señala aquí son sus límites y su rigidez internas, así como su creciente sumisión a intereses capitalistas y a aparatos de dominación hoy en día. Se critica su pretensión de autoasumirse como la única forma de medicina existente, antes, ahora y en el futuro. 


\section{El cuestionamiento al reduccionismo genocentrista en biología y medicina}

Como contraparte a la hegemonía reduccionista en biología y medicina se ha desarrollado una amplia corriente que cuestiona sus bases y fundamentos. Quienes sostienen esta crítica, con diferencias, mantienen un hilo conductor y un argumento central común: Los seres vivos no pueden explicarse solo por la presencia de una molécula maestra que les confiere todas sus propiedades, sino más bien por el conjunto de relaciones y procesos que en ellos ocurren a todos los niveles, incluyendo, en el caso de los humanos, el socio-cultural ${ }^{1}$.

En este sentido se ha venido desmontando la validez universal de los conceptos y mecanismos de herencia dura, del gen como la unidad central de herencia, del DCBM como proceso único y universal de transmisión de información, de las correspondencias estrictas gen-proteína y genotipo-fenotipo, de la mutación como el proceso principal de la variación de los seres vivos, de los criterios tradicionales de especialización y complejidad, del papel pasivo del organismo con respecto al ambiente y de la separación permanente entre estos dos elementos. Se refuta la universalidad de las relaciones causa-efecto 1 a 1 , de los todos como sumas de las partes, y se llama a una pluralidad explicativa, de acuerdo con los niveles ontológicos específicos en cada caso. Se apela a la modificación de los conceptos de prueba y evidencia y al reconocimiento de la imposibilidad de conocerlo todo y de predecir, extrapolar y universalizar principios para sistemas tan complejos como los vivos.

Como parte de ello se viene descubriendo la multiplicidad de flujos de información hereditaria, los mecanismos epigenéticos de herencia (De la Peña y Loyola, 2017; Jablonka, 2005), la realidad de una evolución conductual y cultural independientes de la genética y la epigenética. Se resalta la relevancia de los procesos de "herencia suave", susceptibles a la influencia del ambiente, que hace resurgir la teoría lamarckista y el papel del organismo como agente activo de su propio cambio. El auge de estos estudios de herencia no genética, descartados o menospreciados por la síntesis moderna,

\footnotetext{
1 Como ejemplos tenemos a Levins y Lewontin (op. cit). Lewontin y Levins (2007), Lovelock (1995), Pichot (1999), Gould (2002), Oyama (2000 a, 2000 b), Oyama, et al. (2001) Margulis (2002), Jablonka, (1995, 2005), Gissis y Jablonka (2011); Oddling-Smee, et. al. (2003), Koonin (2012), Tauber (1991, 2017), Sultan (2015), Shapiro (2009, 2011), Stotz, (2006), Dupré (1993, 2002), Rose (1997), Sarkar (1998) y Noble (2006).
} 
conduce a señalar la diversidad de los mecanismos evolutivos y la multiplicidad que en contextos específicos tienen los organismos para responder a estímulos ambientales.

Es materia de debate si estos nuevos hallazgos y teorías llevan a una revolución en las ciencias biológicas o no (Muñoz Rubio, 2018a). Lo que es claro es que ya no se está frente a un bloque monolítico del reduccionismo en biología, que el edificio construido tiene que convivir con un programa de investigación científica alternativo.

\section{Anti-reduccionismo y transformaciones de la ciencia médica}

La importancia de estos descubrimientos y teorías pone de manifiesto que los conceptos de salud y enfermedad, de medicaciones y tratamientos han de evaluarse dentro de un campo complejo de relaciones causa-efecto, parte-todo, individuo-ambiente. Es interesante, en este sentido, comprender el campo fértil de la epigenética, al considerar las influencias no genéticas en la producción de enfermedades y epidemias. ${ }^{2}$ Se posibilita el vínculo con los estudios de la mente: psicología y psicoanálisis, al aceptar el papel de elementos afectivos y anímicos en el origen, desarrollo y tratamiento de las dolencias. Con matices diferentes, esta biología cuestiona las bases del modelo reduccionista-mecanicista en la medicina y puede poner en cuestión la validez universal de la alopatía y su dependencia con la industria farmacéutica.

De acuerdo con estas concepciones, el tratamiento de enfermedades y de los sujetos que las padecen no puede basarse más en una concepción del cuerpo como algo fragmentado en partes independientes o estrictamente determinado por los genes, sino en una evaluación integral que comprenda la interpenetración de los elementos relevantes en las situaciones que producen la enfermedad: elementos genéticos, anatómico-fisiológicos, psicológicos y ambientales. Esto implica mayor modestia de las aspiraciones de universalización de las medicaciones y la capacidad predictiva de los tratamientos, especialmente en lo que se refiere a la aplicación indiscriminada y masiva de antibióticos y vacunas, con una consideración profunda de sus capacidades curativo-preventivas y de sus probados o probables efectos secundarios negativos a corto, mediano y largo plazos. En el caso de las vacunas, señalar

2 Para tener una idea de esto se pueden revisar las publicaciones en journals como Epigenetics, Epigenomics o Clinical Epigenetics, si bien debe advertirse que muchos de los estudios ahí reportados podrían llevar a un determinismo y reduccionismo epigenéticos. 
estas limitaciones no implica sumarse a pronunciamientos sin bases científicas ni racionales como los del llamado "movimiento antivacunas".

En otro orden de cosas, se trata de dejar de concebir al paciente como simple objeto de experimentación, sometido a las órdenes del médico y de la institución en las que se encuentra. La enfermedad y los agentes que la producen deben entenderse como proceso socio-cultural, no solamente como relaciones biológicas aisladas.

Llama la atención en este panorama el hecho de que los grandes consorcios de las industrias farmacéutica y alimentaria hacen caso omiso de los nuevos hallazgos en biología y medicina, y permanecen apegados a teorías, categorías y metodologías anacrónicas: las de la ciencia reduccionista y determinista. Esto se expresa en momentos presentes con la caracterización de la pandemia del SARS-CoV 2 y su tratamiento preventivo, evaluado con base en estadísticas por lo general abstractas y orientado casi exclusivamente hacia las vacunas. Esas concepciones mantienen las obsoletas relaciones de casualidad 1 a 1, la tesis del todo como suma de partes y lo que de ello se deriva.

La industria farmacéutica defiende forzadamente este método no por poseer un alto valor de verdad, sino porque es el que le facilita sus intereses de ganancia. Una metodología basada en causalidades 1 a 1 y en esquemas de variables dependiente-independiente resulta mucho más atractiva para estas corporaciones, porque les permite encontrar con relativa facilidad los resultados que a ellas les conviene. Esto, con desconsideración de probables efectos y consecuencias perjudiciales de sus descubrimientos a mediano y largo plazos; de las interacciones e interpenetraciones entre los niveles de análisis, de los cambios cuantitativo-cualitativos que puedan ocurrir en los sistemas en estudio; de las limitaciones de replicación de los resultados y de sus capacidades predictivas. Lo importante viene siendo la obtención de la mayor cantidad de plusvalía posible en el lapso más corto.

\section{Conclusión}

Las criticas aquí señaladas a la ciencia reduccionista y a su expresión en la medicina son parte de una crítica más general a la visión hegemónica del mundo, la cual, en la coyuntura de esta pandemia, exhibe elementos de una crisis que abarcaría los sistemas de salud y sus presupuestos 
ontológico-epistemológicos. Estos señalamientos apuntan a la conformación de una nueva medicina, integral y humana, respetuosa de la naturaleza, como parte indispensable de una modificación radical de las relaciones sociales y con el mundo natural. Una ciencia médica que muestre mayor apertura hacia las llamadas "terapias alternativas" como homeopatía, acupuntura o herbolaria.

Se invita, pues, a una reflexión presente y futura de esta naturaleza, que llevaría a analizar los conceptos de ciencia, preciencia y pseudociencia; que haga luces acerca de hasta qué punto los discursos de la medicina alternativa serían concepciones que requieren un proceso de maduración para que, en su caso, su práctica y su teoría encuentren el lugar que les corresponde. Debe también profundizarse sobre los elementos sociológicos que han permitido la hegemonía de la medicina alopática reduccionista en detrimento de otras opciones médicas, no reduccionistas. No siempre se trata de un enfrentamiento tajante de "charlatanes" contra "científicos", sino de programas de investigación con líneas epistemológicas y bases ontológicas distintas, pero no necesariamente incompatibles entre sí. Esto debería tener consecuencias positivas en el conocimiento biológico y hacer luces sobre la pertinencia de las vacunas como la única forma preventiva de estas pandemias, de manera análoga a como, en la actualidad, se cuestiona el uso indiscriminado de antibióticos.

No es posible enfrentar a la medicina reduccionista si no es con una concepción alternativa radicalmente diferente. Esta concepción es la dialéctica, el método de la totalidad dinámica, fundado en la filosofía moderna por Hegel $(1951,2001)$ y retomado por Marx y Engels (1977) y por Engels $(1961,1975)$ al referirse a los problemas del mundo natural. Es la dialéctica traída a los problemas de la ciencia biológica contemporánea por estudios como los de Levins y Lewontin (1985), Lewontin y Levins (2007) Lewontin (2000); Rose (1997) Woods y Grant (2002), Sachs (1999), Foster (2000), Muñoz Rubio, (2018b, 2018c), o Royle (2014).

La dialéctica permite abordar los problemas de la naturaleza y su relación con la sociedad de manera más integral, flexible y profunda que el reduccionismo y que otras teorías de sistemas complejos; permite insertar los elementos naturales y sociales, objetivos y subjetivos mediante la metodología basada en el concepto de interpenetración de los opuestos. Rompe 
con las formalidades y abstracciones del reduccionismo y con las de los sistemas complejos por medio del análisis de las totalidades concretas y las determinaciones que las componen. Puede comprender "la contingencia, contradicción e historicidad" de los procesos (Levins, 2007, p. 101). Con ello, el movimiento se presenta con toda su heterogeneidad y plenitud y no como engañosa regularidad y gradualidad; la esencia deja de ser una cosa para comprenderse como proceso, la causalidad son algo más que relaciones 1 a 1 de causa-efecto y los todos son cualitativa y dinámicamente distintos a las partes. Esto permite entender el mundo como transformación radical de las relaciones a los distintos niveles.

Sin este tipo de metodologías, las explicaciones sobre el carácter de la medicina, los problemas que enfrenta y sus posibles soluciones quedarán encerrados en una insatisfactoria parcialidad.

Finalmente, se considera que los argumentos planteados en este texto son fundamentales para comprender la naturaleza de la pandemia del virus SARS-Cov-2 desde un punto de vista de la totalidad. Ni el origen de esta y del virus, ni las medidas tomadas por gobiernos e instituciones, ni los tratamientos médicos presentes y futuros pueden sustraerse por mucho tiempo más a estas observaciones.

\section{Referencias}

Bordieu, P. "El oficio de científico". (Barcelona: Anagrama, 2001).

Bowler, P. "Evolution: The History of an Idea". (Berkeley: University of California Press, 2003).

Caparrós, N., y Cruz Roche, R. (directores) "Viaje a la complejidad”. (Madrid: Biblioteca Nueva, 2012).

Crick, F. “Central Dogma of Molecular” Biology. Nature, 227, (1970) 561-563.

Darwin, C. "The Variation of Plants and Animals under Domestication" (2 vol.). (Baltimore: Johns Hopkins University Press, 1998) [1868].

Darwin, C. "The Origin of Species". (Cambridge, MA: Harvard University Press, 1964) [1859].

De la Mettrie, J. O. "El hombre máquina". (Buenos Aires: Editorial Universitaria de Buenos Aires, 1962) [1747].

De la Peña, C. y Loyola, M. "De la genética a la epigenética." (Ciudad de México: Fondo de Cultura Económica, 2017).

Descartes, R. “Tratado del hombre". (Madrid: Nacional, 1989) [1633].

Descartes, R. "Los principios de la filosofía”. (Madrid: Alianza Universidad, 1995) [1647].

Descartes, R. "Meditaciones metafísicas”. (Madrid: Espasa Calpe, 1996 b) [1628]. 
Descartes, R. "Reglas para la dirección del espíritu”. (Madrid: Alianza Editorial, 1996 b) [1628].

Dupré J. "The Disorder of Things: Metaphysical Foundations of the Disunity of Science". (Cambridge, MA: Harvard University Press, 1993).

Dupré, J. "Humans and Other Animals". (Oxford: Oxford University Press, 2002).

Durkheim, E. "Las reglas del método sociológico.” (México DF: Ediciones Coyoacán, 2001).

Engels, F. “Dialéctica de la naturaleza”. (México DF: Grijalbo, 1961) [1890].

Engels, F. “Anti Dühring”. (México DF: Ediciones de Cultura Popular, 1975) [1894].

Foster, J. B. "La ecología de Marx: Materialismo y naturaleza" (Barcelona: El Viejo Topo, 2000).

Freud, S. "Obras completas". (Madrid: Biblioteca Nueva, 2017).

García, R. "Sistemas complejos. Conceptos, métodos y fundamentación epistemológica de la investigación interdisciplinaria". (Barcelona: Gedisa, 2007).

Gissis, S. B. y Jablonka, E. (Editores) "Transformations of Lamarckism”. (Cambridge, MA: MIT Press, 2011).

González Casanova, P. “Las nuevas ciencias y las humanidades”. (Barcelona: Anthropos, 2004).

Gould, S. J. "The Structure of the Theory of Evolution". (Cambridge, MA: MIT Press, 2002).

Hegel, G. W. F. "Science of Logic". (London: George Allen \& Unwind, 1951) [1812-1816].

Hegel, G. W. F. "Lectures on Logic”. (Bloomington: Indiana University Press, 2001) [1831].

Hobbes, T. "Leviatán.” (México DF: Fondo de Cultura Económica, 2001) [1651].

Hume, D. "A Treatise on Human Nature". (Oxford: Oxford University Press, 1992) [1739-1740].

Hume, D. "Enquires Concerning Human Understanding and Concerning the Priciples of Morals" (Oxford: Oxford University Press, 2000) [1777].

Jablonka, E. y Lamb, M. "Epigenetic Inheritance and Evolution: The Lamarckian Dimension”. (Oxford: Oxford University Press, 1995).

Jablonka, E. y Lamb, M. "Evolution in Four Dimensions: Genetic, Epigenetic, Behavioral and Symbolic Variation in the History of Life". (Cambridge, MA: MIT Press, 2005).

Koonin, E. V. “Does the Central Dogma Still Stand?” Biology Direct, 7, (2012) 27.

Lamarck, J. B. M. "Philosophie Zoologique, ou Exposition Histoire Naturelle des Animaux". ( Paris: De L'Imprmièrie de Duminil-Lesueur, 1809).

Leibniz, G. W. "Monadología”, en Leibniz. (Madrid: Colección Gredos Grandes Pensadores, 2018) [1714].

Levins, R. Dialectics and Systems Theory. En R. Levins y R. C, Lewontin (Eds.), "Biology under the Influence; Dialectical Essays in Ecology, Agriculture and Health". (New York: Monthly Review Press, 2007) 101-124.

Levins. R. y Lewontin, R. C. “The Dialectical Biologist”. (Cambridge, MA:Harvard University Press, 1985).

Lewontin, R. Foreword. En A. I. Tauber (Ed.), "Organism and the Origins of Self. BSPS" Vol. 129, 1991), XIII-XIX.

Lewontin, R. C. "The Triple Helix”. (Cambridge, MA: Harvard University Press, 2000).

Lewontin, R. y Levins, R. "Biology under the Influence; Dialectical Essays on Ecology, Agriculture and Health". (New York: Monthly Review Press, 2007). 
Lovelock, J. “Gaia: A New Look at Life on Earth”. (Oxford: Oxford University Press, 1995).

Locke, J. "Ensayo sobre el entendimiento humano". (México DF: Fondo de Cultura Económica, 2005) [1690].

Margulis, L. "Una revolución en la evolución”. (Valencia: Universitat de Valencia, 2002).

Marx. K. "Tesis sobre Feuerbach, en Marx, K. y F. Engels: Obras escogidas." Moscú: Progreso, (1955) [1845-1846]. Tomo II, 401-403.

Marx, K. [F. Engels] "El capital, Libro III”. (México DF: Siglo XXI, 1985).

Marx, K. "Contribución a la crítica de la economía política". (México DF: Siglo XXI, 1987a) [1859].

Marx, K. "Contribución a la crítica de la economía política". (México DF: Siglo XXI, 1987 b) [1859].

Marx, K. “El capital, Libro I". México DF: Siglo XXI, 1988) [1867].

Marx, K. y Engels, F. “Obras escogidas en dos tomos”. (Moscú: Progreso, 1977).

Mendel, G. "Experiments on Plant Hibridization". (Cambridge, MA: Harvard University Press, 1965) [1866].

Mill, J. S. “A System of Logic: Racionative and Inductive”. (New York: Harpers \& Brothers Publishers, 1904) [1843].

Morín, E. "Introducción al pensamiento complejo". (Barcelona: Gedisa, 2017).

Muñoz Rubio, J. (Coordinador). "La biología evolutiva contemporánea: ¿Una revolución más en ciencia?" (Ciudad de México: UNAM, 2018a)

Muñoz Rubio, J. Dialectics and Neo-Lamarckism against the Fetishim of Genes. En T. Awerbuch, M. S. Clark y P. J. Taylor (Eds.), "The Truth is the Whole: Essays in Honor of Richard Levins". (Arlington, MA: The Pumping Station, 2018b), 24-55.

Muñoz Rubio, J. La revolución en biología como cuestionamiento de las relaciones esencia-apariencia (una crítica al inmanentismo neo-darwinista). En J. Muñoz Rubio (Coordinador), "La biología evolutiva contemporánea ¿una revolución en ciencia?” (Ciudad de México: UNAM, 2018c) 23-69.

Noble, D. “The Music of Life: Biology Beyond Genes ”. (Oxford: Oxford University Press, 2006).

Odling-Smee, F. J, Laland, K. N. y Feldman, M. W. "Niche Construction: The Negelcted Process in Evolution". (Princeton: Pricenton University Press, 2003).

Oyama, S. "The Ontogeny of Information: Developmental Systems and Evolution”. (Durham, NC: Duke University Press, 2000a).

Oyama, S. "Evolution's Eye: A Systems View of the Biology-Culture Divide”. (Durham, NC: Duke University Press, 2000b).

Oyama, S. Griffits, P. E. y Gray, R. D. "Cycles of Contingency: Developmental Systems and Evolution”. (Cambridge, MA: MIT Press, 2001).

Pichot, A. "Historie de la Notion de Gène". (Paris: Flammarion, 1998).

Rose, S. "Lifelines: Biology, Freedom, Determinism”. (London: Penguin, 1997).

Royle, C. "Dialectics, Nature and the Dialectics of Nature". International Socialism, 141, (2014) 97-118.

Sachs, W. "Planet Dialectics: Explorations in Environment \& Development". (Halifax: Ferwood Publishing, 1999). 
Sarkar, S. "Genetics and Reductionism". (Cambridge: Cambridge University Press, 1998). Shapiro, J. A. "Revisiting the Central Dogma in the 21st Century". Annals of the New York Academy of Sciences (Natural Genetic Engineering and Natural Genome Editing), 1178, (2009) 6-28.

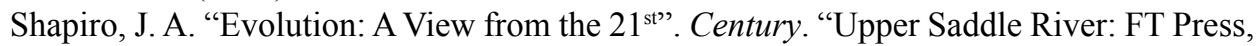
2011).

Smith, A. “The Wealth of Nations”. (London: J. M. Dent \& Sons Ltd. 1954) [1776-1778].

Stearns, S. C. y Coella, J. (Eds.) "Evolution in Health and Disease". (Oxford: Oxford University Press, 2008).

Stotz, K."Molecular Epigenesis: Distributed Specificity as a Break in the Central Dogma", History and Philosophy of the Life Sciences, 26 (3-4), (2006) 527-544.

Sultan, S. E. "Organism and Environment: Ecological Development, Niche Construction, and Adaptation”. (Oxford: Oxford University Press, 2015).

Tauber, I. (Editor). "Organism and the Origins of Self" (Dordrecht: Kluwer Academic Publishers, 1991).

Tauber, I. "Immunity: The Evolution of an Idea”. (Oxford: Oxford University Press, 2017).

Taylor. J. "Body by Darwin: How Evolution Shapes our Health and Transforms Medicine”. (Chicago: University of Chicago Press, 2015).

Watson, J. D. y Crick, F. H. C. "Molecular Structure of Nucelic Acids." Nature, 171. (1953a). 737-738.

Watson, J. D. y Crick, F. H. C. “Genetical Implications of the Structure of the Desoxirribomucleic Acid". Nature, 171. (1953b). 964-967.

Weber, M. "Economía y sociedad". (México DF: Fondo de Cultura Económica, 1964).

Weismann, A. "Studies in the Theory of Descent". (New York: AMS Press, 1882).

Woods, A. y Grant, T. “Razón y revolución: Filosofía marxista y ciencia moderna”. (Madrid: Fundación Federico Engels, 2002). 